\title{
Overexpression of miR-9 in mast cells is associated with invasive behavior and spontaneous metastasis
}

Joelle M Fenger ${ }^{1}$, Misty D Bear², Stefano Volinia ${ }^{3}$, Tzu-Yin Lin ${ }^{4}$, Bonnie K Harrington ${ }^{2}$, Cheryl A London ${ }^{1,2}$ and William C Kisseberth ${ }^{*}$

\begin{abstract}
Background: While microRNA (miRNA) expression is known to be altered in a variety of human malignancies contributing to cancer development and progression, the potential role of miRNA dysregulation in malignant mast cell disease has not been previously explored. The purpose of this study was to investigate the potential contribution of miRNA dysregulation to the biology of canine mast cell tumors (MCTs), a well-established spontaneous model of malignant mast cell disease.

Methods: We evaluated the miRNA expression profiles from biologically low-grade and biologically high-grade primary canine MCTs using real-time PCR-based TaqMan Low Density miRNA Arrays and performed real-time PCR to evaluate miR-9 expression in primary canine MCTs, malignant mast cell lines, and normal bone marrow-derived mast cells (BMMCs). Mouse mast cell lines and BMMCs were transduced with empty or pre-miR-9 expressing lentiviral constructs and cell proliferation, caspase 3/7 activity, and invasion were assessed. Transcriptional profiling of cells overexpressing miR-9 was performed using Affymetrix GeneChip Mouse Gene 2.0 ST arrays and real-time PCR was performed to validate changes in mRNA expression.
\end{abstract}

Results: Our data demonstrate that unique miRNA expression profiles correlate with the biological behavior of primary canine MCTs and that miR-9 expression is increased in biologically high grade canine MCTs and malignant cell lines compared to biologically low grade tumors and normal canine BMMCs. In transformed mouse malignant mast cell lines expressing either wild-type (C57) or activating (P815) KIT mutations and mouse BMMCs, miR-9 overexpression significantly enhanced invasion but had no effect on cell proliferation or apoptosis. Transcriptional profiling of normal mouse BMMCs and P815 cells possessing enforced miR-9 expression demonstrated dysregulation of several genes, including upregulation of CMA1, a protease involved in activation of matrix metalloproteases and extracellular matrix remodeling.

Conclusions: Our findings demonstrate that unique miRNA expression profiles correlate with the biological behavior of canine MCTs. Furthermore, dysregulation of miR-9 is associated with MCT metastasis potentially through the induction of an invasive phenotype, identifying a potentially novel pathway for therapeutic intervention.

Keywords: Mast cell, microRNA, miR-9

\footnotetext{
* Correspondence: kisseberth.2@osu.edu

'Department of Veterinary Clinical Sciences, Columbus, USA

Full list of author information is available at the end of the article
} 


\section{Background}

Mast cell-associated malignancies are important diseases in both humans and dogs $[1,2]$ and are characterized by activating mutations in KIT in both species. More than $90 \%$ of human patients with systemic mastocytosis carry the D816V mutation in KIT [3] which results in constitutive activation of KIT signaling and plays a major role in the proliferative phenotype. A functionally identical mutation (D814V) is found in transformed mast cell lines from rodents [4,5]. Similarly, approximately 30\% of dogs with high-grade cutaneous mast cell tumors (MCTs) possess activating internal tandem duplications (ITDs) in the KIT juxtamembrane (JM) domain [6,7]. More recently, activating mutations in the extracellular domain of KIT (exons 8 and 9) have also been identified in a proportion of canine MCTs [8]. While the role of KIT dysfunction in mast cell neoplasia has been well described, little is known regarding additional molecular mechanisms that may contribute to invasion and metastasis of malignant mast cells.

The expression of matrix metalloproteinases (MMPs), a family of enzymes involved in the degradation and remodeling of extracellular matrix, has been implicated in the neoplastic transformation of mast cells. Normal canine bone marrow-derived mast cells (BMMCs) produce large quantities of inactive and active MMP9 in response to various stimuli while releasing little detectable MMP2 [9]. Neoplastic mast cells are known to produce both MMP2 and MMP9 [10] suggesting that the ability to produce MMP2 may be a feature acquired by malignant mast cells. Furthermore, high-grade MCTs express significantly higher levels of MMP9 in proactive and active forms, which has been proposed to be associated with the high degree of malignant behavior of these tumors $[10,11]$. More recently, characterization of the proteome of primary canine low-grade MCTs and aggressive, high-grade MCTs identified differentially expressed proteins between the two groups [12]. Several stress response proteins (HSPA9, TCP1A, TCP1E) and cytoskeletal proteins associated with actin remodeling and cell migration (WDR1) were significantly up-regulated in high-grade MCTs.

MicroRNAs (miRNAs) are highly conserved, noncoding RNAs that serve as important regulators of gene expression. It is well established that miRNA expression is altered in many human malignancies and that miRNAs function as tumor suppressor genes or oncogenes through dysregulation of target genes [13]. Currently there is limited information regarding the potential role of miRNA dysregulation in malignant mast cell disease. Several miRNAs appear to play an important role in normal murine mast cell differentiation [14] and following activation of murine mast cells, up-regulation of the miR-221-222 family influences cell-cycle checkpoints, in part by targeting $\mathrm{p} 27^{\mathrm{Kip} 1}$ [15]. Basal levels of miR-221 contribute to the regulation of the cell cycle in resting mast cells. However, its effects are activation-dependent and in response to mast cell stimulation; miR-221 regulates degranulation, cytokine production, and cell adherence [16]. More recent studies have demonstrated roles for miR-539 and miR-381 in mediating a novel regulatory pathway between KIT and microphthalmia-associated transcription factor in normal and malignant mast cells [17].

The purpose of this study was to investigate the potential role of miRNA dysregulation in the biologic behavior of primary canine MCTs. We found that unique miRNA expression profiles correlate with the biological behavior of primary canine MCTs and that miR-9 was significantly overexpressed in aggressive MCTs compared to benign MCTs. Furthermore, enforced miR-9 expression in murine mastocytoma cell lines and normal murine BMMCs with low basal levels of miR-9 enhanced invasion and induced the expression of several target genes associated with

Table 1 Primers for quantitative reverse transcriptase polymerase chain reaction

\begin{tabular}{ll}
\hline Primers & Primer sequences \\
\hline Mouse Cma1 292F & 5'-GAA GAC ACG TGG CAG AAG CTT GAG-3' \\
Mouse Cma1 521R & 5'-GTG TCG GAG GCT GGC TCA TTC ACG-3' \\
Mouse Hspe F479 & 5'-GCT CAG TGG ACA TGC TCT ACA G-3' \\
Mouse Hspe R697 & 5'-GCA ACC CAT CGA TGA GAA TGT G-3' \\
Mouse Ifitm3 115F & 5'-GCT TCT GTC AGA ACT ACT GTG-3' \\
Mouse Ifitm3 339R & 5'-GAG GAC CAA GGT GCT GAT GTT CAG-3' \\
Mouse Mlana 125F & 5'-GCT GCT GGT ACT GTA GAA GAC G-3' \\
Mouse Mlana 322R & 5'-GTG AAG AGA GCT TCT CAT AGG CAG-3' \\
Mouse Pdzk1ip1 F520 & 5'-GTT CTG GCT GAT GAT CAC TTG ATT G-3' \\
Mouse Pdzk1ip1 R769 & 5'-GAT AGA AGC CAT AGC CAT TGC TG-3' \\
Mouse SerpinF1 712F & 5'-GTG AGA GTC CCC ATG ATG TCA G-3' \\
Mouse SerpinF1 910R & 5'-GTT CTC GGT CGA TGT CAT GAA TG-3' \\
Mouse TIr7 F2284 & 5'-GTC ATT CAG AAG ACT AGC TTC CCA G-3' \\
Mouse TIr7 R2441 & 5'-GTC ACA TCA GTG GCC AGG TAT G-3' \\
Mouse Cd200r1 659F & 5'-GTA ACC AAT CTC TGT CCA TAG-3' \\
Mouse Cd200r1 902R & 5'-GTC ACA GTA TCA TAG AGT GGA TTG-3' \\
Mouse Cd200r4 312F & 5'-GCC TCC ACA CCT GAC CAC AG-3' \\
Mouse Cd200r4 532R & 5'-GTC CAA GAG ATC TGT GCA GCA G-3' \\
Mouse Perp F108 & 5'-GCA GTC TAG CAA CCA CAT CCA G-3' \\
Mouse Perp R267 & 5'-GCA CAG GAT GAT AAA GCC ACA G-3' \\
Mouse SIpi F142 & 5'-GAG AAG CCA CAA TGC CGT ACT G-3' \\
Mouse Slpi R378 & 5'-GAC TTT CCC ACA TAT ACC CTC ACA G-3' \\
Mouse Pparg F682 & 5'-GAT ATC GAC CAG CTG AAC CCA G-3' \\
Mouse Pparg R983 & 5'-GCA TAC TCT GTG ATC TCT TGC ACG-3' \\
18S V2F & 5'-AAA TCC TाT AAC GAG GAT CCA TT-3' \\
18S V2R & \\
\hline
\end{tabular}


metastasis, including chymase (CMA1) and heparinase (HSPE). These data suggest that miR-9 overexpression may contribute to the invasive phenotype of malignant mast cells thereby providing a potentially novel pathway for therapeutic intervention in malignant mast cell disease.

\section{Methods}

Cell lines, primary cell cultures, primary tumor samples

Mouse P815 (D814V KIT mutation) and C57 (wild-type KIT) cell lines were provided by Dr. Stephen Galli (Stanford University). The canine BR (activating point mutation L575P in the JM domain of KIT) and C2 (KIT ITD mutation in the JM domain) cell lines were provided by Dr. Warren Gold (Cardiovascular Research Institute, University of California- San Francisco). Cell lines were maintained in RPMI 1640 (Gibco ${ }^{\circ}$ Life Technologies, Grand Island, NY, USA) supplemented with $10 \%$ fetal bovine serum (Gibco ${ }^{\circ}$ Life Technologies) and antibiotics (Gibco ${ }^{\circ}$ Life Technologies). Mouse BMMCs were generated from bone marrow from C57/B6 wild-type mice as previously described [9]. Canine BMMCs were generated from 2 dogs and maintained in Stemline (SigmaAldrich, St. Louis, MO, USA) medium supplemented with recombinant canine stem cell factor ( $R$ \& D Systems, Minneapolis, MN, USA) as previously described [18]. Protocols for collection of murine bone marrow and canine bone marrow were approved by the Ohio State University
(OSU) Institutional Care and Use Committee (IACUC), protocols 2009A0204 and 2010A0015, respectively. Canine MCTs were obtained from 24 different affected dogs presented to the OSU Veterinary Medical Center and University of California-Davis (UCD) Veterinary Teaching Hospital. Tumor sample collections were performed in accordance with established hospital protocols and approved by respective IACUC at both OSU and UCD. Clinical outcome data, including sex, breed, primary tumor location, recurrence and metastasis, histopathologic grade, mitotic index, and outcome was available for all dogs (see Additional file 1). Tumors obtained from dogs that were adequately controlled with surgery alone and did not develop or die from metastatic mast cell disease were considered biologically low-grade tumors (benign). Tumors from dogs that developed aggressive, metastatic mast cell disease which resulted in their death were classified as biologically high-grade tumors.

\section{Quantitative reverse-transcription-PCR profiling of mature miRNA expression in MCT biopsies}

Total RNA was isolated by the Trizol method (Invitrogen, Carlsbad, CA, USA) and heparinase treated as described [19]. Primary MCT miRNA expression profiling was performed at the OSU Nucleic Acid Shared Resource using the TaqMan Array Human miRNA Panel (Human A Cards, v.2, Applied Biosystems, Foster City, CA, USA) as

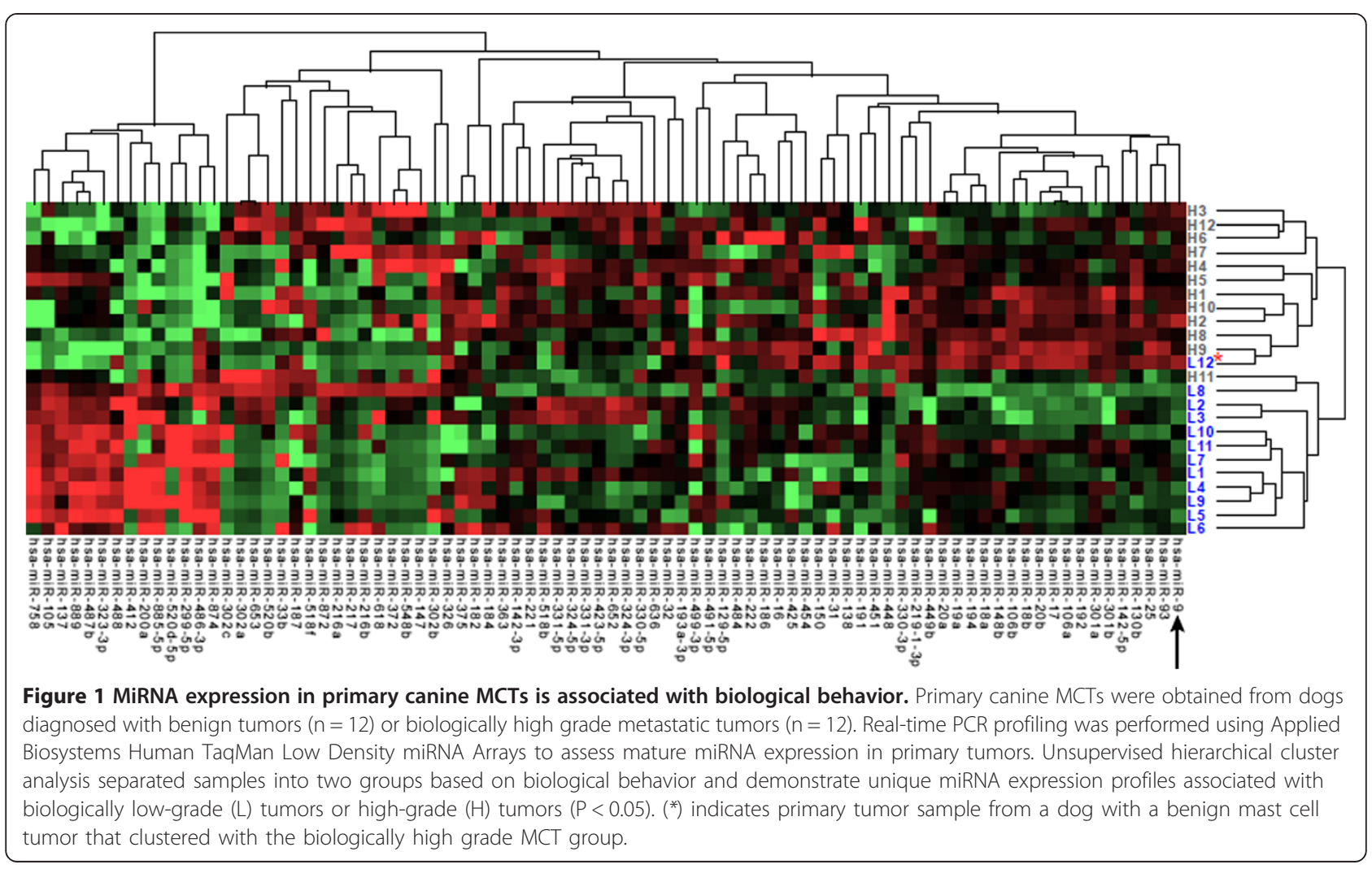


described previously [20]. This panel assays the expression of 377 human miRNAs, 151 of whose mature sequences are 100\% conserved between human and dog (Sanger miRBase v.12). Raw data analysis, normalizer selection and statistical analysis were performed using the real-time PCR analysis software Statminer (Integromics, Madison, WI, USA). The snRNA U6 was confirmed to be stably expressed in our sample set and the mean used as the normalizer value. Relative gene expression was calculated using the comparative threshold cycle method [21]. Gene expression heat maps were generated using Treeview PCbased software [22].

RNA isolation and quantitative real-time PCR

RNA was extracted from cell lines using TRIzol (Invitrogen) and real-time PCR was performed using the
Applied Biosystems StepOne Plus Detection System. MiR-9 is highly conserved and shares 100\% homology between dogs, humans, and mice. Mature miR-9 expression was performed using Taqman miRNA assays (Applied Biosystems). $50 \mathrm{ng}$ total RNA was converted to firststrand cDNA with miRNA-specific primers, followed by real-time PCR with TaqMan probes. All samples were normalized to U6 snRNA.

Real-time PCR was performed to validate changes in mRNA expression for selected genes affected by miR-9 over expression. cDNA was made from $1 \mu \mathrm{g}$ of total RNA using Superscript III (Invitrogen). CMA1, HSPE, IFITM3, MLANA, PERP, PPARG, PDZK1IP1, SERPINF1, SLPI, TLR7, CD200R1, CD200R4 and 18S transcripts were detected using Fast SYBR green PCR master mix (Applied Biosystems) according to the manufacturer's

Table 2 MiRNA signature associated with biologically high-grade MCTs

\begin{tabular}{|c|c|c|c|c|c|}
\hline \multirow[t]{3}{*}{ miRNA } & Fold-change & $p$-value & miRNA & Fold-change & p-value \\
\hline & \multicolumn{3}{|l|}{ Gene expression } & \multicolumn{2}{|l|}{ Gene expression } \\
\hline & \multicolumn{3}{|l|}{ High vs low grade MCT } & \multicolumn{2}{|l|}{ High vs low grade MCT } \\
\hline \multicolumn{6}{|c|}{ Upregulated miRNAs } \\
\hline hsa-miR-301b & 4.2 & 0.00022 & hsa-miR-520b & 1.8 & 1.8 \\
\hline hsa-miR-454 & 2.4 & 0.00032 & hsa-miR-216b & 4.6 & 0.023 \\
\hline hsa-miR-9 & 3.2 & 0.0010 & hsa-miR-302b & 3.2 & 0.024 \\
\hline hsa-miR-147 & 3.9 & 0.0017 & hsa-miR-106b & 1.6 & 0.026 \\
\hline hsa-miR-138 & 2.5 & 0.0022 & hsa-miR-618 & 3.0 & 0.027 \\
\hline hsa-miR-330-5p & 3.1 & 0.0027 & hsa-miR-518f & 3.2 & 0.029 \\
\hline hsa-miR-187 & 5.1 & 0.0029 & hsa-miR-182 & 2.8 & 0.030 \\
\hline hsa-miR-106a & 2.1 & 0.0044 & hsa-miR-142-5p & 1.7 & 0.031 \\
\hline hsa-miR-636 & 2.7 & 0.0052 & hsa-miR-301a & 2.8 & 0.032 \\
\hline hsa-miR-17 & 2.0 & 0.0057 & hsa-miR-217 & 3.9 & 0.033 \\
\hline hsa-miR-449b & 3.2 & 0.0069 & hsa-miR-652 & 2.0 & 0.039 \\
\hline hsa-miR-130b & 2.2 & 0.0082 & hsa-miR-186 & 1.5 & 0.039 \\
\hline hsa-miR-192 & 2.5 & 0.0095 & hsa-miR-19a & 1.8 & 0.040 \\
\hline hsa-miR-448 & 3.1 & 0.010 & hsa-miR-872 & 1.5 & 0.041 \\
\hline hsa-miR-425 & 3.0 & 0.011 & hsa-miR-148b & 1.8 & 0.043 \\
\hline hsa-miR-193a-3p & 2.6 & 0.011 & hsa-miR-451 & 2.4 & 0.044 \\
\hline hsa-miR-18b & 2.2 & 0.014 & hsa-miR-423-5p & 1.7 & 0.048 \\
\hline hsa-miR-93 & 2.1 & 0.014 & hsa-miR-191 & 1.5 & 0.049 \\
\hline hsa-miR-548b-5p & 2.3 & 0.015 & Downregulated miRNAs & & \\
\hline hsa-miR-25 & 2.1 & 0.015 & hsa-miR-885-5p & -4.2 & 0.00011 \\
\hline hsa-miR-324-3p & 2.3 & 0.017 & hsa-miR-874 & -5.8 & 0.00018 \\
\hline hsa-miR-326 & 2.6 & 0.017 & hsa-miR-486-3p & -4.6 & 0.00040 \\
\hline hsa-miR-18a & 3.1 & 0.017 & hsa-miR-299-5p & -4.2 & 0.0020 \\
\hline hsa-miR-20b & 2.0 & 0.017 & hsa-miR-488 & -3.9 & 0.0063 \\
\hline hsa-miR-194 & 2.8 & 0.019 & hsa-miR-200a & -5.5 & 0.034 \\
\hline hsa-miR-372 & 2.4 & 0.019 & hsa-miR-412 & -2.8 & 0.035 \\
\hline
\end{tabular}


protocol; primer sets are detailed in Table 1. Normalization was performed relative to $18 \mathrm{~S}$ rRNA. All reactions were performed in triplicate and included notemplate controls for each gene. Relative gene expression for all real-time PCR data was calculated using the comparative threshold cycle method [21]. Experiments were repeated 3 times using samples in triplicate.

\section{MiR-9 lentivirus infection}

Lentiviral constructs were purchased from Systems Biosciences (Mountain View, CA, USA). Packaging of the lentiviral constructs was performed using the pPACKH1 Lentivector Packaging KIT (catalog no. LV500A-1) according to the manufacturer's instructions. P815 and C57 mouse mastocytoma cells and mouse BMMCs $\left(10^{5}\right.$ cells) were transduced with empty lentivirus (catalog no. CD511B-1) or pre-miR-9-3 lentivirus (catalog no. PMIRH9-3PA-1). FACS-mediated cell sorting based on GFP expression was performed 72 hours post-transduction and miR-9 expression was evaluated by real-time PCR (Applied Biosystems).

\section{Transcriptional profiling of cells transduced with miR-9 lentivirus}

RNA was extracted from mouse BMMCs and P815 cells transduced with empty lentivirus or pre-miR-9-3 lentivirus from three separate transduction experiments using TRIzol (Invitrogen). A secondary RNA cleanup step was performed using QIAGEN RNeasy Total RNA isolation kit (QIAGEN GmbH, Hilden, Germany) and RNA integrity was assessed using RNA 6000 Nano LabChip ${ }^{\oplus}$ Kits on the Agilent Bioanalyzer 2100 (Agilent Technologies, Palo Alto, CA, USA). RNA was labeled with Cy3 using RNA ligase and hybridized to GeneChip ${ }^{\odot}$ Mouse Gene 2.0 ST Arrays (Affymetrix, Santa Clara, CA, USA). Ratios of signals were calculated and transcripts that were up-regulated or down-regulated by at least 2 -fold were identified $(\mathrm{p}<0.05)$. Data analysis, statistical analysis, and generation of gene expression heat maps were performed using Affymetrix ${ }^{\oplus}$ Transcriptome Analysis Console (TAC) Software. Prediction of miR-9 binding to the 3'-UTR of genes down-regulated by miR-9 was performed with computer-aided algorithms obtained from TargetScan (http://www.targetscan.org), PicTar (http://pictar.mdc-berlin.de), miRanda (http://www.microrna.org), and miRWalk (http://www.umm.uni-heidelberg. de/apps/zmf/mirwalk).

\section{Matrigel invasion assay}

To assess the effect of miR-9 expression on invasion, cell culture inserts $(8-\mu \mathrm{m}$ pore size; Falcon) were coated with $100 \mu \mathrm{L}$ of Matrigel (BD Bioscience, San Jose, CA, USA) to form a thin continuous layer and allowed to solidify at $37^{\circ} \mathrm{C}$ for 1 hour. P815 and C57 cell lines, and mouse BMMCs $\left(5 \times 10^{5} / \mathrm{mL}\right)$ transduced with control lentivirus or pre-miR-9-3 lentivirus were prepared in serum-free medium and seeded into each insert (upper chamber) and media containing 10\% fetal bovine serum was placed in the lower chamber. The cells were incubated for 24 hours to permit invasion through the Matrigel layer. Cells remaining on the upper surface of the insert membrane were wiped away using a cotton swab, and cells that had migrated to the lower surface were stained with crystal violet and counted in ten independent $20 \times$ high powered fields for each sample. Experiments were repeated 3 times using samples in triplicate.
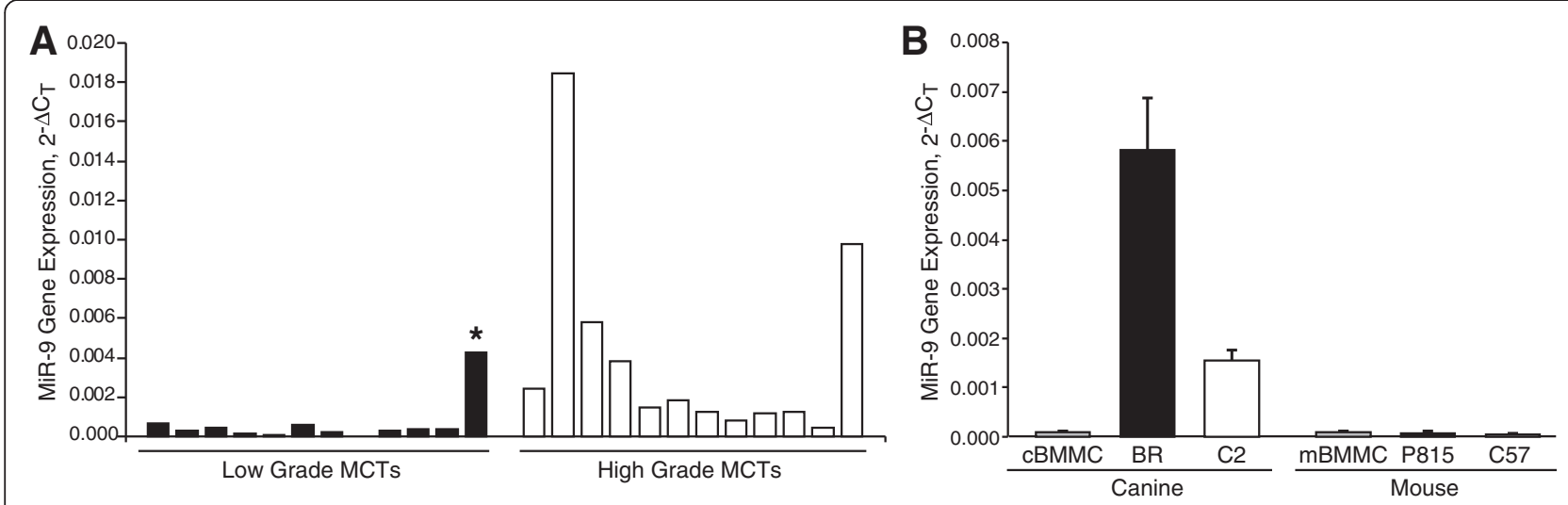

Figure 2 MiR-9 is highly expressed in biologically high grade canine MCTs and malignant mast cell lines. (A) Real-time PCR evaluating mature miR-9 expression in primary canine MCTs demonstrated that the mean expression of miR-9 was 3.2-fold higher in aggressive, high grade MCTs compared to benign MCTs $(p=0.001)$. ( $\left.{ }^{*}\right)$ indicates primary tumor sample from a dog with a low-grade mast cell tumor that expressed high levels of miR-9 but had lymph node metastasis at the time of surgery. (B) Malignant canine BR and C2 mast cells, normal canine and mouse BMMCs, and malignant mouse C57 and P815 cells were cultured and real-time PCR was performed to assess miR-9 expression levels. Three independent experiments were performed and all reactions were performed in triplicate. The experiments were repeated 3 times in the cell lines and twice for normal cBMMCs. 


\section{Evaluation of proliferation and apoptosis}

Changes in cell proliferation were assessed using the CyQUANT $^{\curvearrowleft}$ Cell Proliferation Assay KIT (Molecular Probes, Eugene, OR, USA) as previously described [23]. P815 and C57 cells $\left(15 \times 10^{4}\right)$ transduced with control lentivirus or pre-miR-9-3 lentivirus were seeded in 96-well plates for 24,48 , and 72 hours prior to analysis. Nontransduced P815 and C57 cells served as negative control wells. Fluorescence was measured using a SpectraMax microplate reader (Molecular Devices, Sunnyvale, CA, USA).
Cell proliferation was calculated as a percentage of untransduced control cells.

Caspase-3/7 activity was determined using the SensoLyte ${ }^{\oplus}$ Homogeneous AMC Caspase- 3/7 Assay KIT (Anaspec Inc, San Jose, CA, USA) as previously described [24]. P815 and C57 cells $\left(5.0 \times 10^{4}\right)$ transduced with either empty lentivirus or pre-miR-9-3 lentivirus were plated for 24 and 48 hours in 96-well plates prior to analysis. Fluorescence was measured on a SpectraMax microplate reader (Molecular Devices). Levels of caspase

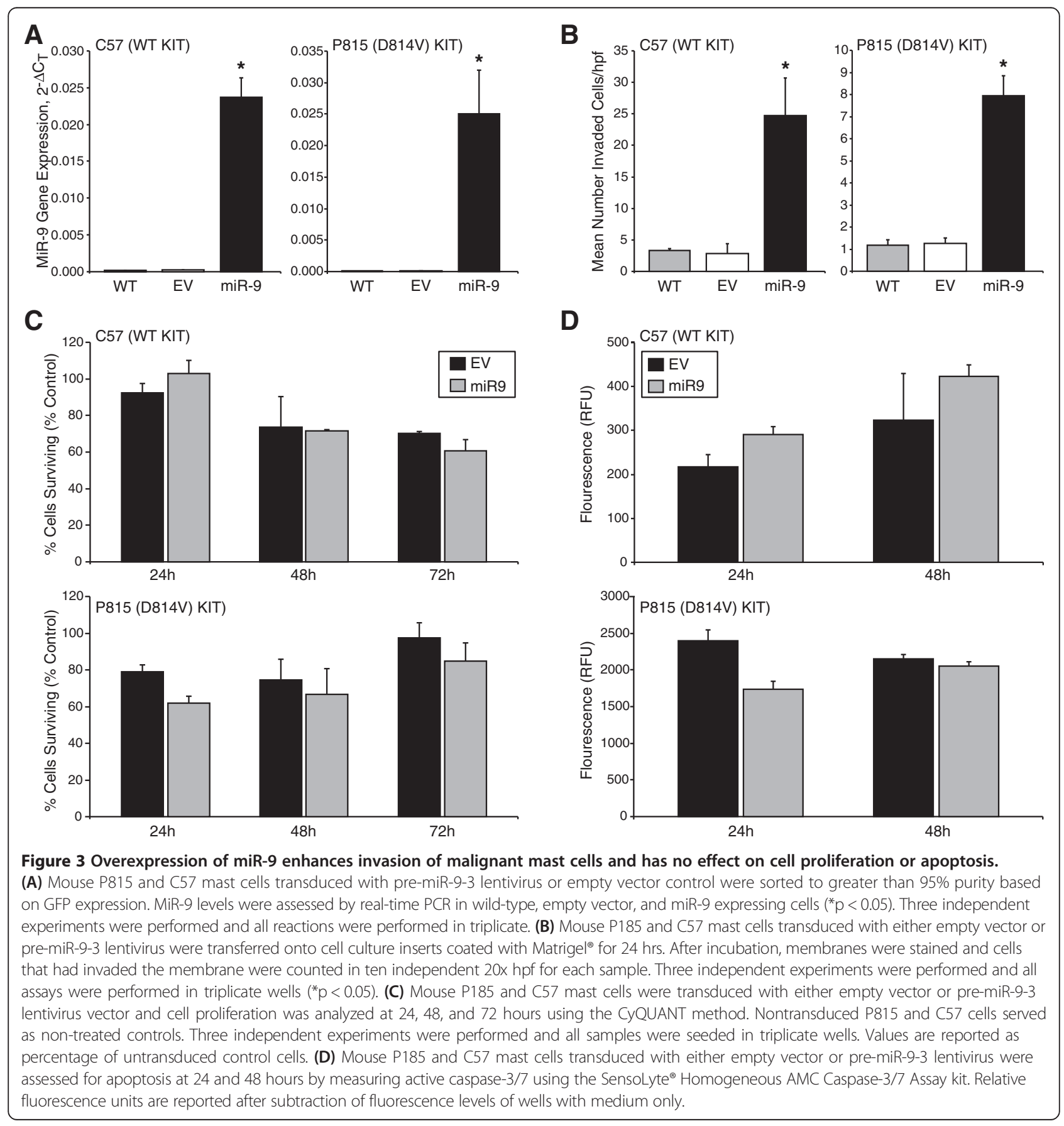


3/7 activity were reported after subtraction of fluorescence levels of wells with medium only.

\section{Statistical analysis}

Statistical analysis relative to miRNA expression data was performed with Statminer software (Integromics) and p-values of $<0.05$ were considered statistically significant. Statistical analysis relative to mRNA expression data was performed using Affymetrix ${ }^{\odot}$ Transcriptome Analysis Console (TAC) Software. Differential gene expression was determined by one-way ANOVA comparison test and p-values of $<0.05$ were considered statistically significant. All experiments with the exception of those involving canine BMMCs were performed in triplicate and repeated 3 times. Experiments using canine BMMCs were performed in triplicate, but repeated only twice because of limited cell numbers. Data were presented as mean plus or minus standard deviation. The difference between two group means was analyzed using the Students $t$-test and a one-way analysis of variance (ANOVA) was performed for multiple variable comparisons. P-values of $<0.05$ were considered significant.

\section{Results}

MiRNA expression in primary canine MCTs is associated with biological behavior

To investigate the role of miRNA dysregulation in the biologic behavior of mast cell disease, global miRNA expression in primary canine MCTs obtained from 24 dogs diagnosed with benign tumors $(\mathrm{n}=12)$ or with biologically high-grade tumors $(\mathrm{n}=12)$ was evaluated using realtime PCR-based TaqMan Low Density miRNA Arrays (Applied Biosystems). An unsupervised hierarchial cluster analysis of all primary MCTs readily separated tumors into groups based on biological behavior with aggressive, highly metastatic MCTs clustering together and clinically benign MCTs clustering together separately (Figure 1). We identified 45 miRNAs that had significantly higher expression in biologically highgrade MCTs compared to biologically low-grade MCTs, while 7 miRNAs had lower expression (Table 2). These data demonstrate that biologically high-grade and lowgrade canine MCTs possess distinct miRNA expression signatures.

\section{miR-9 is overexpressed in biologically high-grade canine MCTs}

The miRNA array performed above identified miR-9 as overexpressed in MCTs that metastasized and resulted in death of affected dogs. This finding was confirmed by real-time PCR in which a 3.2-fold increase in miR-9 expression was identified in biologically aggressive MCTs as compared to benign MCTs (Figure 2A). Furthermore, miR-9 expression correlates with tumor grade and metastatic status in human breast cancer, providing further support for the idea that altered miR-9 expression may be an important regulator of aggressive biological behavior in MCTs (33). Interestingly, one of the primary tumor

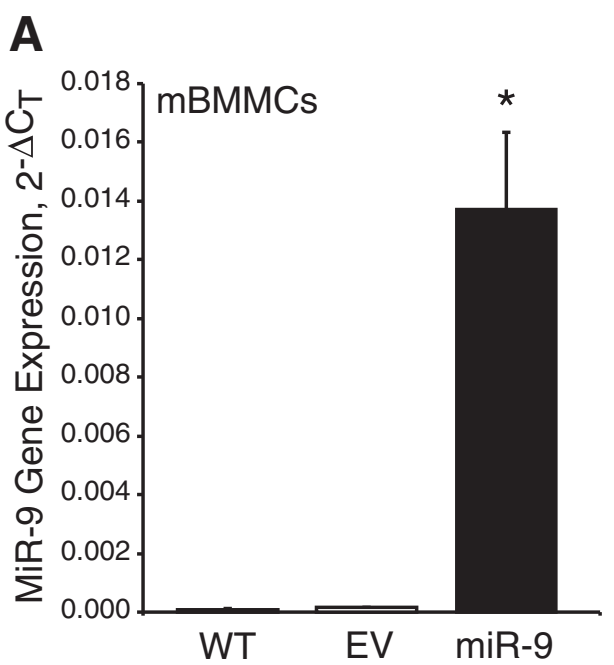

B

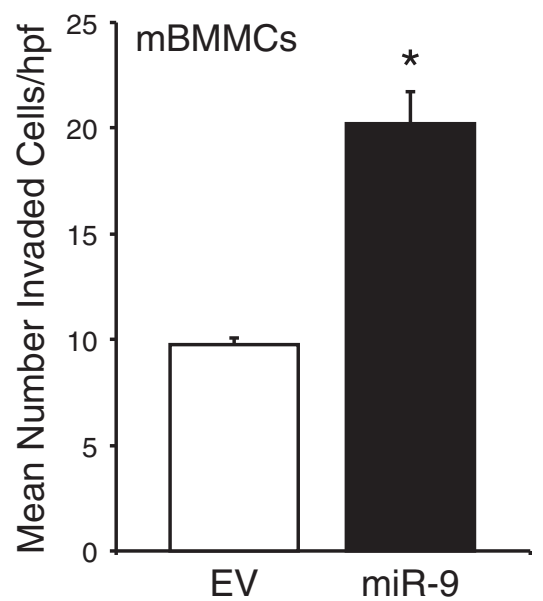

Figure 4 Overexpression of miR-9 enhances invasion in normal mouse bone marrow-derived mast cells. (A) Normal mBMMCs transduced with pre-miR-9-3 lentivirus or empty vector control were sorted to greater than 95\% purity based on GFP expression. MiR-9 levels were assessed by real-time PCR $\left({ }^{*} p<0.05\right)$. Three independent experiments were performed and all reactions were performed in triplicate. (B) mBMMCs transduced with either empty vector or pre-miR-9-3 lentivirus were transferred onto cell culture inserts coated with Matrige ${ }^{\circledR}$ for 24 hrs. After incubation, cells remaining on the upper surface of the insert membrane were wiped away using a cotton swab, and cells that had migrated to the lower surface were stained with crystal violet and counted in ten independent 20x hpf for each sample. Three independent experiments were performed and all samples were performed in triplicate wells $\left({ }^{*} p<0.05\right)$. 

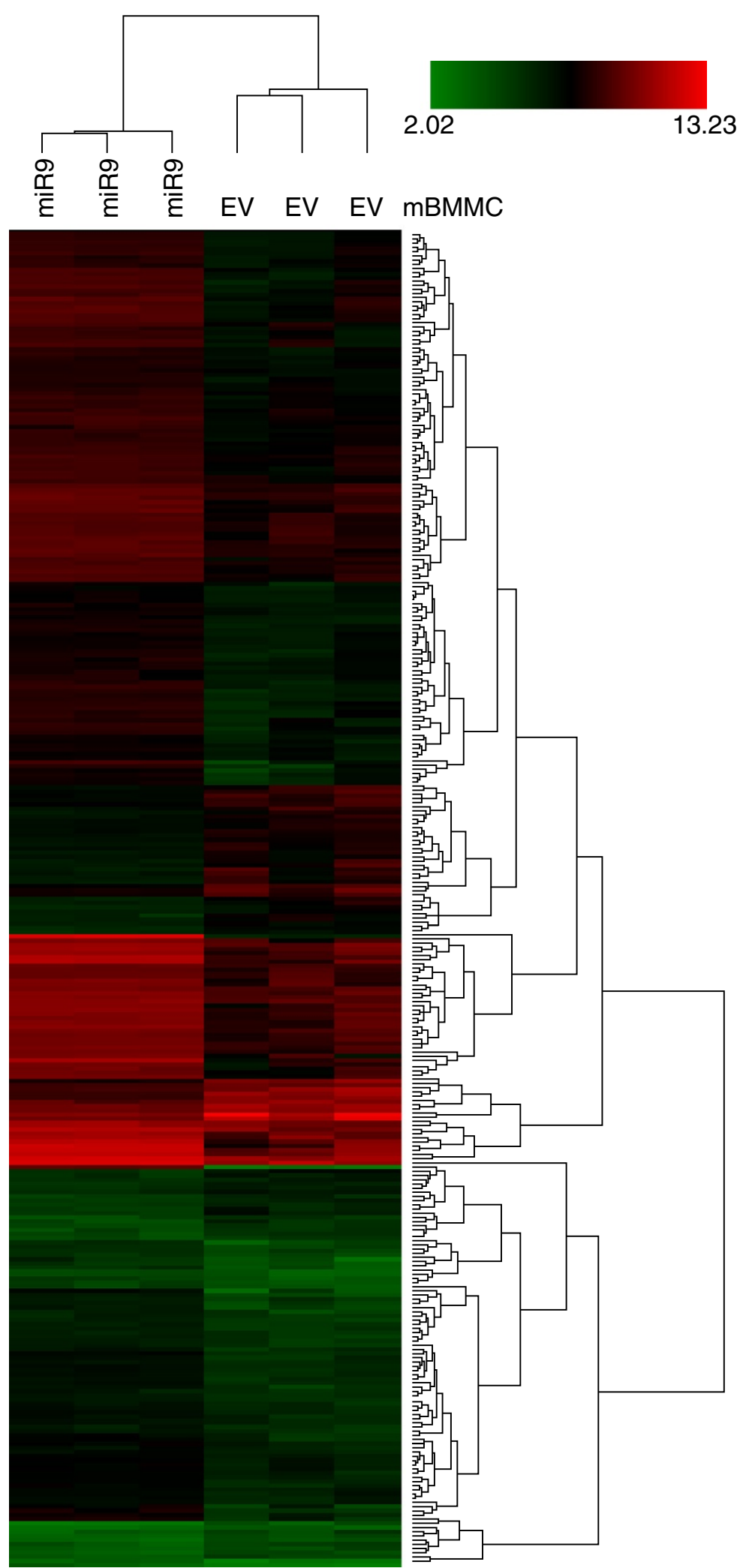

Figure 5 (See legend on next page.) 
(See figure on previous page.)

Figure 5 Overexpression of miR-9 in normal mouse bone marrow-derived mast cells significantly alters gene expression. Normal mBMMCs transduced with pre-miR-9-3 lentivirus or empty vector control were sorted based on GFP expression. RNA was harvested from mouse BMMCs transduced with empty vector or pre-miR-9-3 lentivirus from three separate transduction experiments. Transcriptional profiling was performed using Affymetrix GeneChip ${ }^{\oplus}$ Mouse Gene 2.0 ST Arrays. Hierarchical clustering was performed for 450 genes differentially expressed $(p<0.05)$ in mBMMCs expressing either empty vector (EV) or miR-9 (miR9) as determined by one-way ANOVA comparison test $(p<0.05)$. Mean centered signal intensities of gene-expression are depicted by the log2 of the ratio of the signals against the average signal for each comparison. Color areas indicate relative expression of each gene after $\log 2$ transformation with respect to the gene median expression (red above, green below, and black equal to the mean).

samples collected from a dog with a biologically lowgrade MCT expressed high levels of miR-9 and the unsupervised hierarchial clustering of all 24 MCTs demonstrated that this dog's tumor clustered with the biologically high-grade tumors (Figure 1). Clinical data was subsequently reviewed for all dogs and it was determined that this dog had histopathologically confirmed evidence of metastatic mast cells present in a regional lymph node surgically excised at the time of primary tumor removal. Additionally, one high-grade MCT clustered with the low-grade tumors, however, this may have been due, in part, to variations in stroma/ inflammatory cells within the primary tumor specimen or baseline necrosis within the tumor that influenced the proportion of tumor cells. Taken together, these findings suggest a correlation between miR-9 expression levels in primary canine MCTs and metastatic behavior.

\section{miR-9 expression is up-regulated in canine malignant mast cell lines}

Given the potential link between miR-9 expression and biological behavior of MCTs, we next evaluated miR-9 expression in canine (BR and $\mathrm{C} 2$ ) and murine (C57 and P815) mast cell lines and normal canine and murine BMMCs by real-time PCR. As shown in Figure 2B, canine mastocytoma cells exhibited higher levels of miR-9 expression when compared with normal canine BMMCs. In contrast, both mouse C57 and P815 cells and mouse BMMCs demonstrated low basal levels of miR-9. The mouse P815 mastocytoma cell line is a leukemia of mast cell origin, whereas the canine BR and C2 mastocytoma cells are derived from cutaneous tumors. The differences in the biology of these diseases may account for the observed differences in miR-9 expression in canine and murine cell lines. Low miR-9 expression in P815 cells may reflect the fact that these cells represent a true leukemia, in contrast to the BR and $\mathrm{C} 2$ cell lines which are derived from cutaneous tumors that would metastasize via the lymphatic system. Given prior work from our laboratory showing that the C2 line exhibits invasive behavior in vitro while the P815 line does not [24], it was possible that miR-9 expression was associated with the invasive behavior of mast cells.

\section{Overexpression of pre-miR-9 enhances invasion of malignant mast cell lines}

To investigate the functional consequences of miR-9 overexpression in malignant mast cell lines, we stably expressed miR-9 in the mouse P815 and C57 cell lines that exhibit low basal levels of this miRNA using an empty or pre-miR-9-3 expressing lentivirus vector. Following transduction, GFP + cells were sorted and miR-9 expression was confirmed by real-time PCR (Figure 3A). The invasive capacity of cells was then evaluated using a standard Matrigel invasion assay after 24 hours of culture. As shown in Figure 3B, enforced expression of miR-9 in C57 and P815 mast cell lines significantly enhanced their invasion compared to cells expressing empty vector.

\section{miR-9 has no effect on cell proliferation or caspase-3,7 dependent apoptosis in malignant mast cells}

To investigate whether overexpression of miR-9 in malignant mast cells affected their capacity to proliferate or survive, mouse C57 and P815 cell lines expressing premiR-9-3 lentivirus or empty vector control were cultured for 24,48 , and $72 \mathrm{hrs}$ and the impact on cell proliferation and apoptosis was assessed. No effects of miR-9 on proliferation or apoptosis were observed in either cell line when compared to cells expressing empty vector (Figure 3C and D).

\section{miR-9 expression enhances invasion in normal mouse BMMCs}

To characterize the biological consequences of miR-9 overexpression in normal mast cells, we transduced murine BMMCs with pre-miR-9-3 lentivirus or empty control vector. MiR-9 overexpression in transformed BMMCs was confirmed by quantitative real-time PCR (Figure 4A). To assess the effect of ectopic miR-9 expression on the invasive capacity the BMMCs, a Matrigel invasion assay was again performed. Consistent with findings in the P815 and C57 cell lines, enforced expression of miR-9 in mouse BMMCs significantly enhanced their invasive capacity compared to cells expressing empty vector (Figure 4B). Together, these data suggest that miR-9 promotes an invasive phenotype in mast cells. 
Table 3 Gene transcripts altered by miR-9 overexpression in BMMCs

\begin{tabular}{|c|c|c|}
\hline \multicolumn{3}{|c|}{ Downregulated with miR-9 expression (BMMCs) } \\
\hline 1-Sep & Ell2 & Phgdh \\
\hline 1300014l06Rik & Emp1 & Pi16 \\
\hline 1600029D21Rik & Eya2 & Plk2 \\
\hline 2810025M15Rik & Fn1 & Plod2 \\
\hline 5830428M24Rik & Fzd4 & Ppap2b \\
\hline A2ld1 & Gatm & Pparg \\
\hline Akr1c18 & Glrp1 & Ppic \\
\hline Alox15 & Gm10021 & Prg2 \\
\hline Amigo2 & Gm19524 & Prss34 \\
\hline Ankrd22 & Gm2663 & Psat1, LOC100047252 \\
\hline Ankrd55 & Gm6445 & Rbp4 \\
\hline Arfip1 & Gnpnat1 & Reep6 \\
\hline $\operatorname{Arg} 2$ & Gpc4 & Retnla \\
\hline Asb2 & Gpt2 & Rhoj \\
\hline Asns & Grb10 & Scd1 \\
\hline Atp1b1 & H2-M2 & Scn7a \\
\hline Atp8b4 & $\mathrm{Hal}$ & Serpinb9b \\
\hline Awat1 & $\mathrm{Hdc}$ & Sgce \\
\hline BC100530 & Hgf & Slamf1 \\
\hline Bex1 & II18rap & Slc16a1 \\
\hline Bri3bp & $\| 1 \mathrm{fg}$ & Slc22a3 \\
\hline C87414 & $\| 6 s t$ & Slc36a4 \\
\hline Ccdc88c & Itk & Slc43a3 \\
\hline Ccl17 & Klf5 & Slc7a1 \\
\hline $\mathrm{Ccl} 24$ & Klrb1f & Slc7a5 \\
\hline Ccl8 & Lama5 & Slpi \\
\hline Cd209d & Len2 & Snord70 \\
\hline $\mathrm{Cd} 24 \mathrm{a}$ & LOC100861767 & Speer4e, Gm17019 \\
\hline $\mathrm{Cd} 36$ & LOC100862026 & Stfa2 \\
\hline Cdh17 & Lrrk2 & Stfa2l1 \\
\hline Cdkn2b & Mbnl3 & Sulf2 \\
\hline Celsr1 & Mcpt8 & Syne1 \\
\hline Chi314 & Mgam & Taf1d \\
\hline Clec4e & Mmp13 & Tfrc \\
\hline Colec12 & Mrgpra6 & Thbs 1 \\
\hline Csf3r & Niacr1 & Tm4sf19 \\
\hline Ctsg & Nrg1 & Tmem26 \\
\hline Ctsk & O3far1 & Tnfrsfiob \\
\hline Ctsl & Olr1 & Tspan7 \\
\hline Dennd2d, 2010016118Rik & Pdlim1 & Ube2e2 \\
\hline Dnajc6 & Perp & Vmn1r129 \\
\hline Ear2, Ear12, Ear3 & Pga5 & Zbtb10 \\
\hline Egln3 & Phf10 & Zfp608 \\
\hline
\end{tabular}

Bold indicates predicted miR-9 targets.
Microarray analysis identified genes affected by miR- 9

To gain insight into possible mechanisms underlying the observed miR-9-dependent invasive behavior of mast cells, we compared the transcriptional profiles of murine BMMCs overexpressing miR-9 to those expressing empty vector and found marked changes in gene expression (Figure 5). In BMMCs overexpressing miR-9, 321 transcripts were significantly up-regulated ( $>2$-fold) and 129 transcripts were significantly down-regulated (Table 3, Table 4). Bioinformatic analysis identified putative miR-9 target sites within the 3'-UTR of 40 gene transcripts that were significantly down-regulated with miR-9 overexpression, suggesting that miR-9 may directly target and regulate expression of these candidate genes (Table 3, bolded). Real time PCR confirmed that one of these genes, peroxisome proliferator-activated receptor $\delta$ (PPARG) was down-regulated, a finding consistent with recent studies demonstrating regulation of PPARG by miR-9 through direct targeting of its 3'-UTR [25]. We performed real-time PCR to validate changes in gene expression for several transcripts altered by miR-9 overexpression in BMMCs. Consistent with our microarray results, we found that transcripts for HSPE and TLR7 were significantly up-regulated in BMMCs expressing miR-9, whereas transcripts for PPARG, PERP, and SLPI were significantly down-regulated compared to empty vector controls (Figure 6A).

Similar transcriptional profile analysis was performed using malignant mouse P815 cells and we identified 46 transcripts significantly up-regulated ( $>2$-fold) and 48 transcripts significantly down-regulated in the miR-9 expressing P815 cells (Table 5). Bioinformatic analysis identified putative miR-9 target sites within the 3'-UTR of 15 gene transcripts that were significantly downregulated following miR-9 overexpression, suggesting that miR-9 may directly regulate these genes (Table 5 , bolded). Real-time PCR demonstrated that expression of SERPINF1 and MLANA transcript was up-regulated in P815 cells overexpressing miR-9, whereas CD200R1 and CD200R4 was down-regulated compared to empty vector controls (Figure 6B).

A comparison of the transcriptional profiles both from normal BMMCs and malignant P815 cells overexpressing miR-9 found that most gene transcripts altered by miR-9 were specific to normal or malignant mast cells. We identified 7 gene transcripts (IFITM3, PDZK1IP1, CMA1, MGL1, TMEM223, SLAMF1, CLEC4E) that showed similar changes in expression following miR-9 overexpression in both BMMCs and P815 cells. We performed real-time PCR to validate changes in gene expression for several transcripts altered by miR-9 overexpression, including mast cell chymase (CMA1), interferon-induced transmembrane protein 3 (IFITM3), and PDZK1 interacting protein 1 (PDZK1IP1). Consistent with our microarray results, real-time PCR confirmed that enforced miR-9 expression 
Table 4 Gene transcripts altered by miR-9 overexpression in BMMCs

\begin{tabular}{|c|c|c|c|}
\hline \multicolumn{4}{|c|}{ Upregulated with miR-9 expression (BMMCs) } \\
\hline $1810011 \mathrm{H} 11 \mathrm{Rik}$ & Ddx60 & $\operatorname{lrg} 1$ & Plxna1 \\
\hline 2310028H24Rik & Dnaja4 & Itgb5 & Plxnb3 \\
\hline $3110043021 \mathrm{Rik}$ & Dpep2 & Kcnab3 & Plxnc1 \\
\hline 4930420K17Rik & Dusp22 & Kcne3 & Ppargc1a \\
\hline 5033411D12Rik & E130215H24Rik & Kctd12 & Ppfibp2 \\
\hline 5430435G22Rik & E330020D12Rik & Kctd6 & Ppp1r14c \\
\hline 6330415B21Rik & Ednra & Khdcla & $\begin{array}{l}\text { Prdx1, } \\
\text { LOC100862012 }\end{array}$ \\
\hline 9030625A04Rik & Egr1 & Kit & Prickle1 \\
\hline 9430070013Rik & Emx2 & Klf2 & Psd3 \\
\hline 9930111J21Rik2 & Epsti1 & Klk1b1 & Psg23 \\
\hline A130040M12Rik & $\mathrm{Esco} 2$ & Klk1b11 & Ptafr \\
\hline A230098N10Rik & Esr1 & Klk1b27 & Ptger2 \\
\hline A430084P05Rik & Evl & Klk1b5 & Ptplad2 \\
\hline A4galt & F13a1 & $\mathrm{Kmo}$ & Ptpn13 \\
\hline Abi3 & Fabp5 & Lce6a & Qpct \\
\hline Adamtsl3 & Fabp5, Gm3601 & LOC100038947 & Rasgrp3 \\
\hline Adrb2 & Fam125b & LOC100861753 & Rassf4 \\
\hline Al593442 & Fam55d & LOC100861977 & Rbm47 \\
\hline Al607873 & Fam69a & LOC100862646 & $\operatorname{Rin} 2$ \\
\hline Alcam & Fcgr4 & Lphn1 & Rnase4, Ang \\
\hline Alpk2 & Fkbp1b & Lrp1 & Rnase6 \\
\hline Ank & Fos & Lrrc16a & Rnf180 \\
\hline Ano3 & Fpr2 & Lrrc25 & Rny1 \\
\hline Aoah & Galnt10 & Lrrtm1 & Rps6ka2 \\
\hline Apobec1 & Galnt|4 & Ltf & Rsph9 \\
\hline $\mathrm{Ar}$ & Gas6 & Ly6i & Rtp4 \\
\hline Arhgap20 & Gbp3 & Lyz1 & Ryr3 \\
\hline Arhgap24 & Gbp4 & Maf & Scn1b \\
\hline Arhgap31 & Gbp5 & Mast4 & Scpep1 \\
\hline Arl5b & Gbp8 & Mc1r & Serpinb8 \\
\hline Asphd2 & Gbp9 & Mecom & Siglec1 \\
\hline Bank1 & Gcet2 & $\mathrm{Mgl2}$ & Sirpb1a \\
\hline BC013712 & Gdf15 & Mgll & Sirpb1b \\
\hline Bcl2a1b, Bcl2a1a & Gdpd1 & Mir15b & Slc30a2 \\
\hline $\begin{array}{l}\text { Bcl2a1d, Bcl2a1a, } \\
\text { Bcl2a1b }\end{array}$ & Ggh & Mir181a-1 & Slc37a2 \\
\hline Bhlhe41 & Glul & Mir3095 & Slc39a4 \\
\hline Bmpr2, Gm20272 & $\begin{array}{l}\text { Gm11711, } \\
\text { Cd300lh }\end{array}$ & Mir3108 & Slc40a1 \\
\hline Bst1 & Gm12250 & Mir511 & Slc4a11 \\
\hline Bst2 & Gm14446 & Mir701 & Slc6a12 \\
\hline$C 1 q b$ & Gm15915 & Mlph & Slc9a9 \\
\hline $\mathrm{Clqc}$ & Gm1673 & Mmp2 & Slfn5 \\
\hline
\end{tabular}

Table 4 Gene transcripts altered by miR-9 overexpression in BMMCs (Continued)

\begin{tabular}{|c|c|c|c|}
\hline C330018A13Rik & Gm1966 & Mnda, Ifi204 & Smpdl3b \\
\hline C5ar1 & Gm20099 & Mpeg1 & Smpx \\
\hline Cacnb4 & Gm4759 & Mrgpra9 & $\begin{array}{l}\text { Snord14e, } \\
\text { Hspa8 }\end{array}$ \\
\hline Cadm3 & Gm4951 & Mrgprb2 & St3gal5 \\
\hline Car8 & Gm5431 & Ms4a4a & St6galnac3 \\
\hline $\mathrm{Ccl} 2$ & Gm7977 & Ms4a6b & Stab1 \\
\hline $\mathrm{Ccl} 4$ & Gmpr & Ms4a6c & Stfa3 \\
\hline $\mathrm{Ccl} 7$ & Gna14 & Ms4a6d & Sult1a1 \\
\hline Cond 1 & Gp1ba & Ms4a7 & Syn2 \\
\hline Cornl1 & Gp5 & Msr1 & Syngr1 \\
\hline $\mathrm{Ccr3}$ & Gpm6a & Mtss1 & Tdrd5 \\
\hline Ccr5 & Gpr55 & Nav1 & Tek \\
\hline $\mathrm{Ccrl} 2$ & Grap2 & Neb & Tgfbr2 \\
\hline $\mathrm{Cd} 14$ & H2-DMa & Nlrp1b & Trr1 \\
\hline $\mathrm{Cd} 180$ & $\mathrm{H} 2-\mathrm{DMb} 2$ & Nlrp1c & Trr13 \\
\hline Cd200r2 & $\begin{array}{l}\text { H2-Q6,H2-Q8, } \\
\text { LOC68395 }\end{array}$ & Npy1r & Tlr7 \\
\hline $\mathrm{Cd} 28$ & Hey2 & Nrn1 & Tlr9 \\
\hline $\mathrm{Cd} 300 \mathrm{a}$ & Hist1h1d & Oas2 & Tmem106a \\
\hline cd300lb & Hist1h1e & Oasl2 & Tmem233 \\
\hline Cd300ld & Hist1h2bg & Olfr1033 & Tmem86a \\
\hline $\mathrm{Cd} 86$ & Hist2h3b & Olfr110 & Tnfrsfib \\
\hline $\mathrm{Cdh} 2$ & Hist2h4 & Olfr111 & Tns1 \\
\hline Chst15, Gm10584 & Hist3h2a & Olfr1392 & Trem1 \\
\hline Cited4 & Hist4h4 & Olfr1393 & Trim30c \\
\hline Clec4a1 & Hivep2 & Olfr915 & Trim30d \\
\hline Clec4d & Hpse & Olfr916 & Trim58 \\
\hline Clec4n & Hsd3b6 & Olfr917 & Trpc6 \\
\hline Cma1 & ler2 & Olfr918 & $\operatorname{Tsc} 22 \mathrm{~d} 3$ \\
\hline Cma2 & Ifi204 & Orm3 & Tspan13 \\
\hline Cmklr1 & Ifi27|2a, Ifi27|2b & $P 2 r \times 7$ & Tspan8 \\
\hline Creb5 & Ifitm3 & P2ry6 & Tubb2b \\
\hline Csfir & Ifitm6 & Pcdhga10 & Txk \\
\hline Ctnna2 & Ighm & Pcdhgb6 & Ugt1a10 \\
\hline Ctsh & $\operatorname{lgk}-V 28$ & Pdzk1ip1 & Unc93b1 \\
\hline $\mathrm{C} \times 3 \mathrm{Cr} 1$ & $\| 18$ & Pgap1 & Zbp1 \\
\hline Cybb & $\| 2$ ra & Pid1 & Zbtb8a \\
\hline Cyp4a12a & $\| 6 r a$ & Pion & Zfhx3 \\
\hline Dab2 & lqsec3 & Pld2 & \\
\hline Darc & Irf5, Tnpo3 & $\mathrm{Pld} 4$ & \\
\hline Dbc1 & Irf8 & Plekhm3 & \\
\hline
\end{tabular}




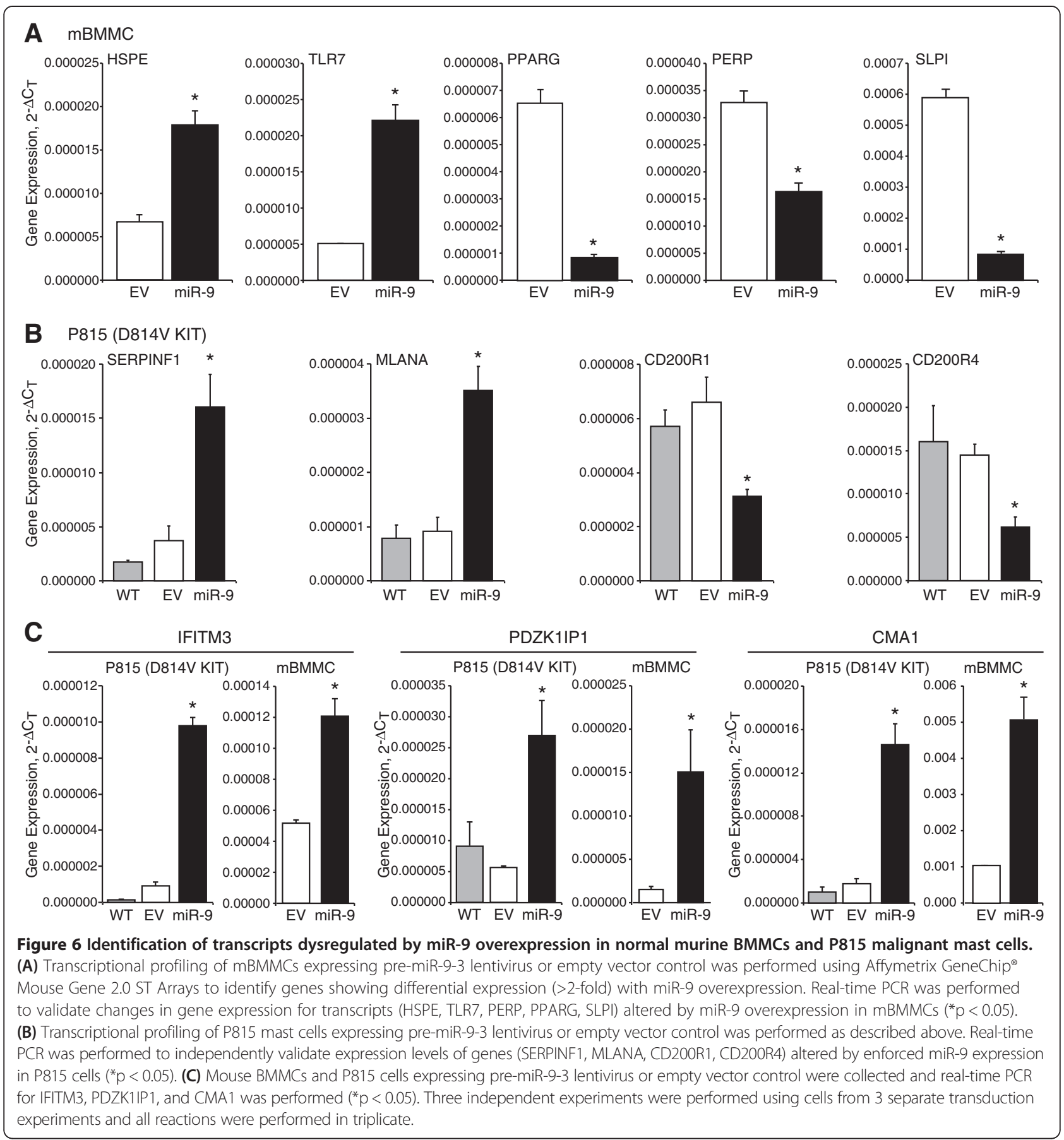

significantly upregulated CMA1, IFITM3, and PDZK1IP1 transcripts in mouse BMMCs and P815 cells (Figure 6C). These findings provide further support for the notion that miR-9 induces alterations in gene expression that may contribute to the development of an invasive phenotype.

\section{Discussion}

MiRNAs regulate various biological functions in normal cells such as growth and differentiation, and they are increasingly recognized as playing critical roles in cancer development and progression. Dysregulation of miRNA expression resulting from amplification or loss of miRNAs in tumors compared to their normal tissue counterparts suggests that miRNAs can function as either oncogenes or tumor suppressor genes [13]. Studies evaluating miRNA expression in spontaneously occurring tumors in dogs demonstrate that similar to human cancers, alteration of miRNAs likely contributes to tumorigenesis and that high- 
Table 5 Gene transcripts altered by miR-9 overexpression in P815 mast cells

\begin{tabular}{|c|c|}
\hline $\begin{array}{l}\text { Upregulated with miR-9 } \\
\text { expression (P815) }\end{array}$ & $\begin{array}{l}\text { Downregulated with miR-9 } \\
\text { expression (P815) }\end{array}$ \\
\hline Ifitm3 & Ligp1 \\
\hline Pdzk1ip1 & Ppm1j \\
\hline Cma1 & Gbp2 \\
\hline Pfkp & Hist2h3c1 \\
\hline Serpinf1 & Ly6a \\
\hline Trim63 & Cd200r1 \\
\hline As3mt & Gzmb \\
\hline Speg & Gbp6 \\
\hline Mlana & Afp \\
\hline Mgl1 & Ifit1 \\
\hline Tmem223 & Parp14 \\
\hline Fjx1 & Ctla2a \\
\hline Vamp5 & lgtp \\
\hline Cthrc1 & Slamf1 \\
\hline Ptgis & Tnfrsf9 \\
\hline Ass1 & Cpa3 \\
\hline Ahi1 & Ctla2b \\
\hline Akap13 & Tgtp//Tgtp2 \\
\hline Prf1 & Rabgap1l \\
\hline Ston2 & Clec4e \\
\hline $\mathrm{Hcfcl}$ & Parp9 \\
\hline Trak1 & Plekha1 \\
\hline Ankrd6 & $\| 1 \mathrm{rl} 1$ \\
\hline Atn1///Rnu7 & Sdf2|1 \\
\hline Fam122b & Gvin1 \\
\hline Mll1 & II2ra \\
\hline Zbtb12 & Fcgr1 \\
\hline Ahnak & Gfil \\
\hline $\operatorname{Sec} 14 \mid 1$ & Thoc1 \\
\hline Mknk2 & Hist1h2ad \\
\hline Apobec2 & Tmed7 \\
\hline Tspan32 & Ugt1a1 \\
\hline Hnrnpl & Taf7l \\
\hline Serbp1 & Slc13a2 \\
\hline Msi2 & Cd200r4 \\
\hline Myl9 & Vegfc \\
\hline Runx2 & Oasl2 \\
\hline Gstm1 & Socs3 \\
\hline Epb4.114b & $677168 / / / \operatorname{lsg} 15$ \\
\hline LOC100041694 & Ctso \\
\hline 2310051F07Rik & Adam8 \\
\hline Arx///LOC100044440 & Samd9| \\
\hline Mest & 1810014B01Rik \\
\hline
\end{tabular}

Table 5 Gene transcripts altered by miR-9 overexpression in P815 mast cells (Continued)

\begin{tabular}{ll}
\hline Mpp4 & LOC641050 \\
Rp131 & Lrrc28 \\
Sphk1 & Hist2h2be \\
& Ebi3 \\
& lgf1 \\
\hline
\end{tabular}

Bold indicates predicted miR-9 targets.

throughput methodologies used for the study of miRNAs in human tissues can also be applied to dogs [26-32].

Cutaneous MCTs are the most common skin tumor in dogs; however, little is known regarding mechanisms underlying malignant transformation of these cells. The biological behavior of canine MCTs ranges from relatively benign disease cured with surgical removal to aggressive, highly metastatic tumors ultimately resulting in the death of affected dogs. While the presence of activating KIT mutations helps to explain the behavior of some canine MCTs, little is known regarding the potential role of miRNAs in both normal and malignant mast cells. The purpose of this study was to begin to investigate the potential role of miRNA dysregulation in canine MCTs that exhibit aggressive biologic behavior.

MiRNA expression profiling of primary canine MCTs identified unique miRNA signatures associated with aggressive MCTs as compared to benign MCTs. The unsupervised hierarchical clustering of primary cutaneous MCTs based on their miRNA expression profiles recapitulated the grouping of the tumors based on their biological behavior, supporting the notion that miRNA dysregulation is associated with the biologic behavior of canine MCTs. Furthermore, we found that miR-9 expression was significantly upregulated in aggressive MCTs compared to benign MCTs. Interestingly, miR-9 was identified as a pro-metastatic miRNA in human breast cancer cell lines through its ability to enhance cell motility and invasiveness in vitro and metastasis formation in vivo [33]. More recently, miR-9 expression was found to be significantly increased in paired primary tumors and distant metastatic sites, suggesting direct involvement of miR-9 in the metastatic process $[34,35]$. In concordance with the potential role of miR-9 in malignant mast cell behavior, the $\mathrm{BR}$ and $\mathrm{C} 2$ canine malignant cell lines expressed high levels of miR-9 compared to normal canine BMMCs. Taken together, these data support the notion that dysregulation of miR-9 may contribute to the aggressive biologic behavior of some canine MCTs.

While activating KIT mutations clearly contribute to the malignant behavior of mast cells, additional cooperating or initiating genetic defects may be required for the malignant transformation and promotion of the 
metastatic phenotype [3]. Our data demonstrate that overexpression of miR-9 in the C57 and P815 mouse malignant mast cell lines and normal mouse BMMCs significantly enhanced the invasive behavior of mast cells and indicate that miR-9 induces a pattern of gene dysfunction associated with an invasive phenotype regardless of KIT mutation status.

While some studies have shown that miR-9 promotes metastasis formation [33,36-39] other contrasting studies suggest that increased expression of miR-9 suppresses metastasis formation $[40,41]$ and that miR-9 inhibits tumor growth [42]. The opposing roles of miR-9 in various tissues may be explained by the expression of different mRNA targets in distinct cellular and developmental contexts. Indeed, miRNA effects do appear to be cell type/ tissue specific and contextual in nature. Previous studies have demonstrated that miR-9 is overexpressed in CDX2negative primary gastric cancers and miR-9 knockdown inhibits proliferation of human gastric cancer cell lines [43]. In contrast, miR-9 is downregulated in human ovarian tumor cells and overexpression of miR-9 suppresses their proliferation, in part by downregulating $\mathrm{NF}_{\kappa} \mathrm{B} 1$ [40,42]. Moreover, miRNA dysregulation may affect only certain aspects of cell behavior. In our studies, miR-9 expression in mast cell lines did not provide a survival advantage or prevent apoptosis, but it did alter the invasive phenotype, supporting the contextual nature of miR-9 induced effects.

To gain insight into possible mechanisms underlying the observed miR-9-dependent invasive behavior of mast cells, we evaluated the effects of miR-9 expression on the transcriptional profiles of BMMCs and P815 cells. MiR-9 modulated the expression of a large number of gene transcripts, including down-regulation of several putative miR-9 targets identified by computational prediction programs. Furthermore, down-regulation of peroxisome proliferator-activated receptor $\delta$ (PPARG) was observed in BMMCs following enforced miR-9 expression, a finding consistent with recent studies demonstrating that regulation of PPARG expression is mediated by miR-9 through direct targeting of its 3'-UTR [25]. To draw firm conclusions regarding direct regulation of target gene expression by miR-9, a functional approach for each gene would be required to validate whether these genes are true miR-9 targets, which although relevant, was outside the scope of this study.

Overexpression of miR-9 significantly altered gene expression in both BMMCs and P815 cells, however, most gene transcripts affected by miR-9 expression differed between normal and malignant mast cells. These observed differences likely reflect variations in the impact of miR-9 that are dependent on cellular context. In our study, we identified gene transcripts that showed similar changes in expression following miR-9 overexpression in both normal and malignant mast cells and validated several genes demonstrating significant changes in expression (interferon-induced transmembrane protein protein 3, IFITM3; PDZK1 interacting protein 1, PDZK1IP1) or implicated in promoting the metastatic phenotype (mast cell chymase, CMA1). IFITM3 belongs to a family of interferon-induced transmembrane proteins that contribute to diverse biological processes, such as antiviral immunity, germ cell homing and maturation, and bone mineralization. The function of these proteins in mast cells is currently unclear [44]. PDZK1IP1 is a small, nongycosylated membrane-associated protein that localizes to the plasma membrane and Golgi apparatus. While the function of PDZK1IP1 has not been evaluated in mast cells, overexpression of PDZK1IP1 has been documented in human ovarian, breast, and prostate carcinomas and this strongly correlates with tumor progression $[45,46]$. Furthermore, overexpression of PDKZK1IP1 in melanoma cell lines enhances cell proliferation, decreases apoptosis, increases cell migration and is, in part, mediated by an increase in reactive oxygen species (ROS) production [47].

Chymases are serine proteases possessing chymotrypsinlike activity expressed exclusively by mast cells that promote matrix destruction, tissue remodeling and modulation of immune responses by hydrolyzing chemokines and cytokines [48]. Given the role of chymase in the activation of matrix metalloproteases and extracellular matrix degradation, our findings suggest that miR-9 enhances invasion, in part, through increased expression chymase. Indeed, miR-9 overexpression in normal mast cells resulted in increased expression of CMA1 with a concomitant decrease in the expression of secretory leukocyte peptidase inhibitor (SLPI), a direct inhibitor of chymase [49]. These findings are consistent with the notion that that miR-9 promotes a pattern of gene expression contributing to enhanced invasion and suggests a role for chymase in mediating the biologic functions of miR-9.

Interestingly, miR-9 modulated the expression of other proteases in normal mast cells, including up-regulation of heparinase (HSPE). Heparinase is an endogylocosidase that functions in the degradation and release of heparan sulfate-bound growth factors [50]. Previous studies have shown that enzymatic cleavage of heparin sulfate by heparinase results in disassembly of the extracellular matrix and basement membrane dissolution, inducing structural modifications that loosen the extracellular matrix barrier and enable cell invasion [51]. Heparinase increases tumor invasion in both cell lines and spontaneous tumor models, through both extracellular matrix remodeling and increased peritumoral lymphangiogenesis [52]. Our data show that normal mast cells overexpressing miR-9 exhibit markedly increased HSPE expression, supporting the assertion that miR-9 may 
promote the metastatic phenotype by enhancing the proteolytic activity of a number of proteases important in physical remodeling of the extracellular matrix and activate mediators responsible for cell dissemination.

The present study investigated alterations in gene transcript expression affected by miR-9; however, these changes were not demonstrated at the protein level. Gene expression does not directly correlate with changes at the protein level and miRNAs may suppress protein expression by post-transcriptional silencing mechanisms that are not reflected in transcriptional profiling analyses. Furthermore, inhibition of miR-9 in canine mast cell lines would provide further convincing evidence of its importance in mast cell invasion. As such, identifying proteins altered by miR- 9 that promote cell invasion and validating these targets in canine cell lines/tumors represents an area of ongoing investigation.

\section{Conclusion}

In summary, the work presented here is the first to demonstrate that unique miRNA expression profiles correlate with the biological behavior of canine MCTs. Furthermore, overexpression of miR-9 is associated with aggressive biologic behavior of canine MCTs, possibly through the promotion of a metastatic phenotype as demonstrated by enhanced invasive behavior of normal and malignant mast cells and alteration of gene expression profiles associated with cellular invasion in the presence of enforced miR-9 expression. Future work to dissect the exact mechanisms through which miR-9 exerts the invasive phenotype is ongoing with the ultimate goal of identifying potential druggable targets for therapeutic intervention.

\section{Additional file}

\section{Additional file 1: Clinical patient data.}

\section{Competing interest}

The authors declare no competing financial interests.

\section{Authors' contributions}

Contribution: JF designed and performed research, analyzed data, and wrote manuscript; MDB and BKH assisted with $\mathrm{MBMMC}$ and primary MCT sample preparation; TYL generated preliminary data that led to work with miRNA and mast cells, assisted with CBMMC and primary MCT sample preparation; SV performed biostatistic analysis; WCK and CAL assisted in research design, oversaw data analysis, writing and editing of paper. All authors read and approved the final manuscript

\section{Acknowledgements}

This study was supported by a grant from the Morris Animal Foundation (D09CA-060), The Ohio State University Targeted Investment in Excellence (TIE) Grant, the National Cancer Institute (P03CA016058), and OSU Center for Clinical and Translational Science (UL1TR000090). Tumor samples were provided by The Ohio State University College of Veterinary Medicine Biospecimen Repository.

\section{Author details}

${ }^{1}$ Department of Veterinary Clinical Sciences, Columbus, USA. ${ }^{2}$ Department of Veterinary Biosciences, Columbus, USA. ${ }^{3}$ Department of Molecular Virology, Immunology, and Medical Genetics, The Ohio State University, Columbus, $\mathrm{OH}$, USA. ${ }^{4}$ Division of Hematology and Oncology, Department of Internal Medicine, University of California-Davis, Sacramento, CA, USA.

Received: 7 October 2013 Accepted: 27 January 2014

Published: 11 February 2014

\section{References}

1. Horny HP, Sotlar K, Valent P: Mastocytosis: state of the art. Pathobiology 2007, 27(2):121-132.

2. London CA, Seguin B: Mast cell tumors in the dog. Vet Clin North Am Small Anim Pract 2003, 33(3):473-489.

3. Valent $P$, Akin C, Sperr WR, Mayerhofer M, Födinger M, Fritsche-Polanz R, Sotlar K, Escribano L, Arock M, Horny HP, Metcalfe DD: Mastocytosis: pathology, genetics, and current options for therapy. Leuk Lymphoma 2005, 46(1):35-48.

4. Tsujimura T, Furitsu T, Morimoto M, Isozaki K, Nomura S, Matsuzawa Y, KITamura Y, Kanakura Y: Ligand-independent activation of c-KIT receptor tyrosine kinase in a murine mastocytoma cell line P-815 generated by a point mutation. Blood 1994, 83(9):2619-2626.

5. Tsujimura T, Furitsu T, Morimoto M, Kanayama Y, Nomura S, Matsuzawa Y, KITamura Y, Kanakura Y: Substitution of an aspartic acid results in constitutive activation of c-KIT receptor tyrosine kinase in a rat tumor mast cell line RBL-2H3. Int Arch Allergy Immunol 1995, 106(4):377-385.

6. Downing S, Chien MB, Kass PH, Moore PE, London CA: Prevalence and importance of internal tandem duplications in exons 11 and 12 of c-KIT in mast cell tumors of dogs. Am J Vet Res 2002, 63(12):1718-1723.

7. Zemke D, Yamini B, Yuzbasiyan-Gurkan V: Mutations in the juxtamembrane domain of c-KIT are associated with higher grade mast cell tumors in dogs. Vet Pathol 2002, 39(5):529-535.

8. Letard S, Yang Y, Hanssens K, Palmérini F, Leventhal PS, Guéry S, Moussy A, Kinet JP, Hermine O, Dubreuil P: Gain-of-function mutations in the extracellular domain of KIT are common in canine mast cell tumors. $\mathrm{Mol}$ Cancer Res 2008, 6(7):1137-1145.

9. Lin TY, London CA: A functional comparison of canine and murine bone marrow derived cultured mast cells. Vet Immunol Immunopathol 2006, 114(3-4):320-334.

10. Leibman NF, Lana SE, Hansen RA, Powers BE, Fettman MJ, Withrow SJ, Ogilvie GK: Identification of matrix metalloproteinases in canine cutaneous mast cell tumors. J Vet Intern Med 2000, 14(6):583-586.

11. Giantin M, Aresu L, Benali S, Aricò A, Morello EM, Martano M, Vascellari M, Castagnaro M, Lopparelli RM, Zancanella V, Granato A, Mutinelli F, Dacasto M: Expression of matrix metalloproteinases, tissue inhibitors of metalloproteinases and vascular endothelial growth factor in canine mast cell tumours. J Comp Pathol 2012, 147(4):419-429.

12. Schlieben $P$, Meyer A, Weise C, Bondzio A, Einspanier R, Gruber AD, Klopfleisch R: Differences in the proteome of high-grade versus low-grade canine cutaneous mast cell tumours. Vet J 2012, 194(2):210-214

13. Garzon R, Fabbri M, Cimmino A, Calin GA, Croce C: MicroRNA expression and function in cancer. Trends Mol Med 2006, 12(12):580-587.

14. Monticelli S, Ansel KM, Xiao C, Socci ND, Krichevsky AM, Thai TH, Rajewsky N, Marks DS, Sander C, Rajewsky K, Rao A, Kosik KS: MicroRNA profiling of the murine hematopoietic system. Genome Biol 2005, 6(8):R71.

15. Mayoral RJ, Pipkin ME, Pachkov M, van Nimwegen E, Rao A, Monticelli S: MicroRNA-221-222 regulate the cell cycle in mast cells. J Immunol 2009, 182(1):433-445.

16. Mayoral RJ, Deho L, Rusca N, Bartonicek N, Saini HK, Enright AJ, Monticelli S: MiR-221 influences effector functions and actin cytoskeleton in mast cells. PLoS One 2011, 6(10):e26133.

17. Lee YN, Brandal S, Noel P, Wentzel E, Mendell JT, McDevitt MA, Kapur R, Carter M, Metcalfe DD, Takemoto CM: KIT signaling regulates MITF expression through miRNAs in normal and malignant cell proliferation. Blood 2011, 117(13):3629-3640.

18. Lin TY, Rush $\sqcup$, London CA: Generation and characterization of bone marrow-derived cultured canine mast cells. Vet Immunol Immunopathol 2006, 113(1-2):37-52. 
19. Tsai M, Miyamoto M, Tam SY, Wang ZS, Galli SJ: Detection of mouse mast cell-associated protease mRNA. Heparinase treatment greatly improves RT-PCR of tissues containing mast cell heparin. Am J Pathol 1995, 146(2):335-343.

20. Guerau-de-Arellano M, Smith KM, Godlewski J, Liu Y, Winger R, Lawler SE, Whitacre CC, Racke MK, Lovett-Racke AE: Micro-RNA dysregulation in multiple sclerosis favours pro-inflammatory T-cell-mediated autoimmunity. Brain 2011, 134(Pt 12):3578-3589.

21. Livak KJ, Schmittgen TD: Analysis of relative gene expression data using real-time quantitative PCR and the 2(-Delta Delta $C(T)$ ) method. Methods 2001, 25(4):402-408

22. Eisen MB, Spellman PT, Brown PO, Botstein D: Cluster analysis and display of genome-wide expression patterns. Proc Natl Acad Sci USA 1998, 95(25):14863-14868.

23. Fossey SL, Liao AT, McCleese JK, Bear MD, Lin J, Li PK, Kisseberth WC, London CA: Characterization of STAT3 activation and expression in canine and human osteosarcoma. BMC Cancer 2009, 9:81.

24. Lin TY, Fenger J, Murahari S, Bear MD, Kulp SK, Wang D, Chen CS, Kisseberth WC, London CA: AR-42, a novel HDAC inhibitor, exhibits biological activity against malignant mast cell lines via down-regulation of constitutively activated KIT. Blood 2010, 115(21):4217-4225.

25. Thulin P, Wei T, Werngren O, Cheung L, Fisher RM, Grander D, Corocran M, Ehrenborg E: MicroRNA-9 regulates the expression of peroxisome proliferator-activated receptor $\delta$ in human monocytes during the inflammatory response. Int J Mol Med 2013, 31(5):1003-1010.

26. Boggs RM, Wright ZM, Stickney MJ, Porter WW, Murphy KE: MicroRNA expression in canine mammary cancer. Mamm Genome 2008, 19(7-8):561-569.

27. Uhl E, Krimer P, Schliekelman P, Tompkins SM, Suter S: Identification of altered microRNA expression in canine lymphoid cell lines and cases of B- and T-cell lymphomas. Genes Chromosomes Cancer 2011, 50(11):950-967.

28. Gioia G, Mortarino M, Gelain ME, Albonico F, Ciusani E, Forno I, Marconato L, Martini V, Comazzi S: Immunophenotype-related microRNA expression in canine chronic lymphocytic leukemia. Vet Immunol Immunopathol 2011, 142(3-4):228-235.

29. Noguchi S, Mori T, Hoshino Y, Yamada N, Maruo K, Akao Y: MicroRnAs as tumour suppressors in canine and human melanoma cells and as a prognostic factor in canine melanomas. Vet Comp Oncol 2013, 11(2):113-123

30. Noguchi S, Mori T, Hoshino Y, Yamada N, Nakagawa T, Sasaki N, Akao Y, Maruo K: Comparative study of anti-oncogenic microRNA-145 in canine and human malignant melanoma. J Vet Med Sci 2012, 74(1):1-8.

31. Vinall RL, Kent MS, DeVere White RW: Expression of microRNAs in urinary bladder samples obtained from dogs with grossly normal bladders, inflammatory bladder disease, or transitional cell carcinoma. Am J Vet Res 2012, 73(10):1626-1633.

32. Wagner S, Willenbrock S, Nolte I, Escobar HM: Comparison of non-coding RNAs in human and canine cancer. Front Genet 2013, 4:46.

33. Ma L, Young J, Prabhala H, Pan E, Mestdagh P, Muth D, Teruya-Feldstein J, Reinhardt F, Onder TT, Valastyan S, Westermann F, Speleman F, Vandesompele J, Weinberg RA: MiR-9, a MYC/MYCN-activated microRNA, regulates E-cadherin and cancer metastasis. Nat Cell Biol 2010, 12(3):247-256

34. Gravgaard KH, Lyng MB, Laenkholm AV, Søkilde R, Nielsen BS, Litman T, Ditzel HJ: The miRNA-200 family and miRNA-9 exhibit differential expression in primary versus corresponding metastatic tissue in breast cancer. Breast Cancer Res Treat 2012, 134(1):207-217.

35. Wang J, Zhao H, Tang D, Wu J, Yao G, Zhang Q: Overexpressions of microRNA-9 and microRNA-200c in human breast cancers are associated with lymph node metastasis. Cancer Biother Radiopharm 2013, 28(4):283-288.

36. Tan HX, Wang Q, Chen LZ, Huang XH, Chen JS, Fu XH, Cao LQ, Chen XL, Li W, Zhang LJ: MicroRNA-9 reduces cell invasion and E-cadherin secretion in SK-Hep-1 cells. Med Oncol 2010, 27(3):654-660.

37. Sun Z, Han Q, Zhou N, Wang S, Lu S, Bai C, Zhao RC: MicroRNA-9 enhances migration and invasion through KLF17 in hepatocellular carcinoma. $\mathrm{Mol}$ Oncol 2013, 7(5):884-894.

38. Lu MH, Huang CC, Pan MR, Chen HH, Hung WC: Prospero homeobox 1 promotes epithelial-mesenchymal transition in colon cancer cells by inhibiting E-cadherin via miR-9. Clin Cancer Res 2012, 18(23):6416-6425.
39. Zhu L, Chen H, Zhou D, Bai R, Zheng S, Ge W: MicroRNA-9 up-regulation is involved in colorectal cancer metastasis via promoting cell motility. Med Oncol 2012, 29(2):1037-1043.

40. Laios A, O'Toole S, Flavin R, Martin C, Kelly L, Ring M, Finn SP, Barrett C, Loda M, Gleeson N, D'Arcy T, McGuinness E, Sheils O, Sheppard B, $\mathrm{O}^{\prime}$ Leary J: Potential role of miR-9 and miR-223 in recurrent ovarian cancer. Mol Cancer 2008, 7:35.

41. Zheng L, Qi T, Yang D, Qi M, Li D, Xiang X, Huang K, Tong Q: MicroRNA-9 suppresses the proliferation, invasion and metastasis of gastric cancer cells through targeting cyclin D1 and Ets1. PLoS One 2013, 8(1):e55719.

42. Guo LM, Pu Y, Han Z, Liu T, Li YX, Liu M, Li X, Tang H: MicroRNA-9 inhibits ovarian cancer cell growth through regulation of NF-kappaB1. FEBS $J$ 2009, 276(19):5537-5546.

43. Rotkrua P, Akiyama Y, Hashimoto Y, Otsubo T, Yuasa Y: MiR-9 downregulates CDX2 expression in gastric cancer cells. Int J Cancer 2011, 129(11):2611-2620.

44. Diamond MS, Farzan M: The broad-spectrum antiviral functions of IFIT and IFITM proteins. Nat Rev Immunol 2013, 13(1):46-57.

45. Guijarro MV, Leal JF, Fominaya J, Blanco-Aparicio C, Alonso S, Lleonart M Castellvi J, Ruiz L, Ramon y Cajal S, Carnero A: MAP17 overexpression is a common characteristic of carcinomas. Carcinogenesis 2007, 28(8):1646-1652.

46. Carnero A: MAP17, a ROS-dependent oncogene. Front Oncol 2012, 2:112. doi:10.3389/fonc.2012.00112.

47. Guijarro MV, Leal JF, Blanco-Aparicio C, Alonso S, Fominaya J, Lleonart M, Castellvi J, Carnero A, Ramon y Cajal S: MAP17 enhances the malignant behavior of tumor cells through ROS increase. Carcinogenesis 2007, 28(10):2096-2104.

48. Caughey $\mathrm{GH}$ : Mast cell tryptases and chymases in inflammation and host defense. Immunol Rev 2007, 217:141-154.

49. He SH, Chen P, Chen HQ: Modulation of enzymatic activity of human mast cell tryptase and chymase by protease inhibitors. Acta Pharmacol $\sin$ 2003, 24(9):923-929.

50. Bashkin P, Razin E, Eldor A, Vlodavsky I: Degranulating mast cells secrete an endoglycosidase that degrades heparan sulfate in subendothelial extracellular matrix. Blood 1990, 75(11):2204-2212

51. Arvatz G, Shafat I, Levy-Adam F, llan N, Vlodavsky l: The heparanase system and tumor metastasis: is heparanase the seed and soil? Cancer Metastasis Rev 2011, 30:253-268.

52. Hunter KE, Palermo C, Kester JC, Simpson K, Li J-P, Tang LH, Klimstra DS, Vlodavsky I, Joyce JA: Heparanase promotes lymphangiogenesis and tumor invasion in pancreatic neuroendocrine tumors. Oncogene 2013:1-10. doi:10.1038/onc.2013.142

\section{doi:10.1186/1471-2407-14-84}

Cite this article as: Fenger et al:: Overexpression of miR-9 in mast cells is associated with invasive behavior and spontaneous metastasis. BMC Cancer 2014 14:84.

\section{Submit your next manuscript to BioMed Central and take full advantage of:}

- Convenient online submission

- Thorough peer review

- No space constraints or color figure charges

- Immediate publication on acceptance

- Inclusion in PubMed, CAS, Scopus and Google Scholar

- Research which is freely available for redistribution 